\title{
A Proposed System to Manage Donations to Improve Public Schools and Colleges Academic Standings
}

\author{
Mohammed H. S. Al Ashry (Ashry) ${ }^{1}$ \\ ${ }^{1}$ Department of Computer Science, the Community College; Department of Computer Science, the College of \\ Sciences and Humanities, Shaqra University, Shaqra, Saudi Arabia \\ Correspondence: Mohammed H. S. Al Ashry (Ashry), Department of Computer Science, the Community College; \\ Department of Computer Science, the College of Sciences and Humanities, Shaqra University, Shaqra, Saudi Arabia. \\ Tel: 966-55-990-0033. \\ Received: August 7, 2017 \\ Accepted: August 18, 2017 \\ Online Published: September 13, 2017 \\ doi:10.5430/ijba.v8n6p22 \\ URL: https://doi.org/10.5430/ijba.v8n6p22
}

\begin{abstract}
Public schools are usually financed with governments' grants, typically included in the annual budget. In the United States, financial donations are encouraged by the governing bodies and sanctioned by the deductible charitable contributions' taxing system. This paper proposes a donation-contribution scheme to strategically enhance education. The process is planned, developed and arranged by volunteers, schools' principles-deans, and supervised by special members of the board of education. It involves special charity events and prearranged private visual demonstrations. Wealthy individuals and Corporate heads like to take advantage of the taxing deductible system to eliminate taxing of inappropriate financial write offs by subscribing to benevolent charitable activities. In Saudi Arabia, however, financial donations to public schools are non-existent. This paper provides preliminary partial draft code, and develops an example of a processing procedure for acquiring donations utilizing a reliable cost effective technique.
\end{abstract}

Keywords: Donations: goodwill contributions, taxing deductible: income deductibles subject to goodwill contributions or family-related deductions, DFD: dataflow diagrams detailing system and code design, AFD: activity flow diagram charting the decision flow, ERD: entity relationship diagram illustrating the relationship between the main entities

\section{Literature Review}

Academic literature on donations to schools is very limited, however, donations to education in general is very popular amongst people of all classes. Academic papers, if any, cover the legal taxing topics in relation to goodwill contributions and donations to education in general. Aspects of using donations and financial contributions to lower or eliminate taxes are researched in details.

It is important to emphasize that this paper focuses on donations and financial contributions to pre-college or pre-higher education institutes. The main premise centers on the ways through which schools communicate with donors; and how donations are collected and distributed. Schools are assumed to have complete control over the methods of soliciting financial contributions and their distributions following guidelines, with monitoring, of the department of education in their respective state (Ong, Paul; Jiménez, Silvia; Parent, Bill; Ong, Elena (2014), “The State of Donations: Individual Charitable Giving in Los Angelos").

\section{Introduction}

Managing financial donations is a business process subject to scrutiny and doubt. Donations are bestowed to many entrusted goodwill establishments whose objectives helping the poor, nonprofit public health research and educational institutions. There are many methods for obtaining donations, private or public grants and or support from privately funded endowments and charities.

For an education institute, or a public school, the process of enticing financial funding involves all levels of the schools' faculty members, administrators and select volunteers. Volunteers are usually approached during the students' registration period. Volunteers can be parents, relatives, friends of the parents or designated members of the school or department of education. Volunteers can also be donors, as long as their donations do not influence or induce the kids' grades. In order to reach our goal of acquiring donations a procedural processing system is designed 
to manage the enrollment and registration of the students and the volunteers. This process provides us with data relating the school's size to the quality and quantity of the donations and grants.

The accrued donations, capital and other forms of needed material will be defined and specified prior to the actual process of pursuing donors. Certain projects, subject to size and cost, are delegated to large donors, such as corporations and or wealthy individuals. Charity events are a venue to obtain donations of all forms through and from volunteers and others. Soliciting of and lobbying for large projects should be delegated to specific capable and experienced volunteers and school employees to schedule meetings with corporate heads and wealthy donors.

\section{The Approach}

Acquiring donations can be an exhausting process (Note 1). A database-software to manage the activities is necessary to gather and catalogue records on volunteers, donors, charity events, and all aspects of the donations. A decision flow chart DFC, or an activity flow diagram AFD, establishes the functional activity flow of the planners. Planning functions, identifying potential volunteers and donors are done in the initial stages of the software's system's analysis, which designates the main entities and relationships. Setting up charity events, corporate engagements and logging the final draft list of volunteers, invitees, donors, corporation heads establish the groundwork and facilitate success. Exceeding the average annual contribution requires a lot of planning (Clemen, Rober t T, 1995, $2^{\text {nd }}$ edition). Dataflow diagramming DFD facilitates understanding of the previous steps. Scheduling charity events and corporate engagements concludes the activities leading to the final stage of securing donations. This process simplifies diagramming the DFDs. ADF and DFDs simplify the coding of the software. Finally, a cost effective list of average donations is utilized to reach the highest financial contributions possible.

\section{The Methodology}

DFD, entity relations diagrams ERD, and activity flow diagrams, AFD, respectively, are partly essential for augmenting the volunteers' and donors' selection. Determining the expense and budgeting for the related activities follows the previously mentioned functions (Eisner, Howard; (1997), 61-65). Defining the type of donations and contributions according to proposed charity events, personal visual demonstrations and professional interactivity propagates the school's message and further its value to donors. The previous history of donations will be used to gauge and estimate the eventual size of the contributions.

The following diagram Figure 1, illustrates the context DFD of the school system (Martin, James, \& McClure, Carma. (1988)).

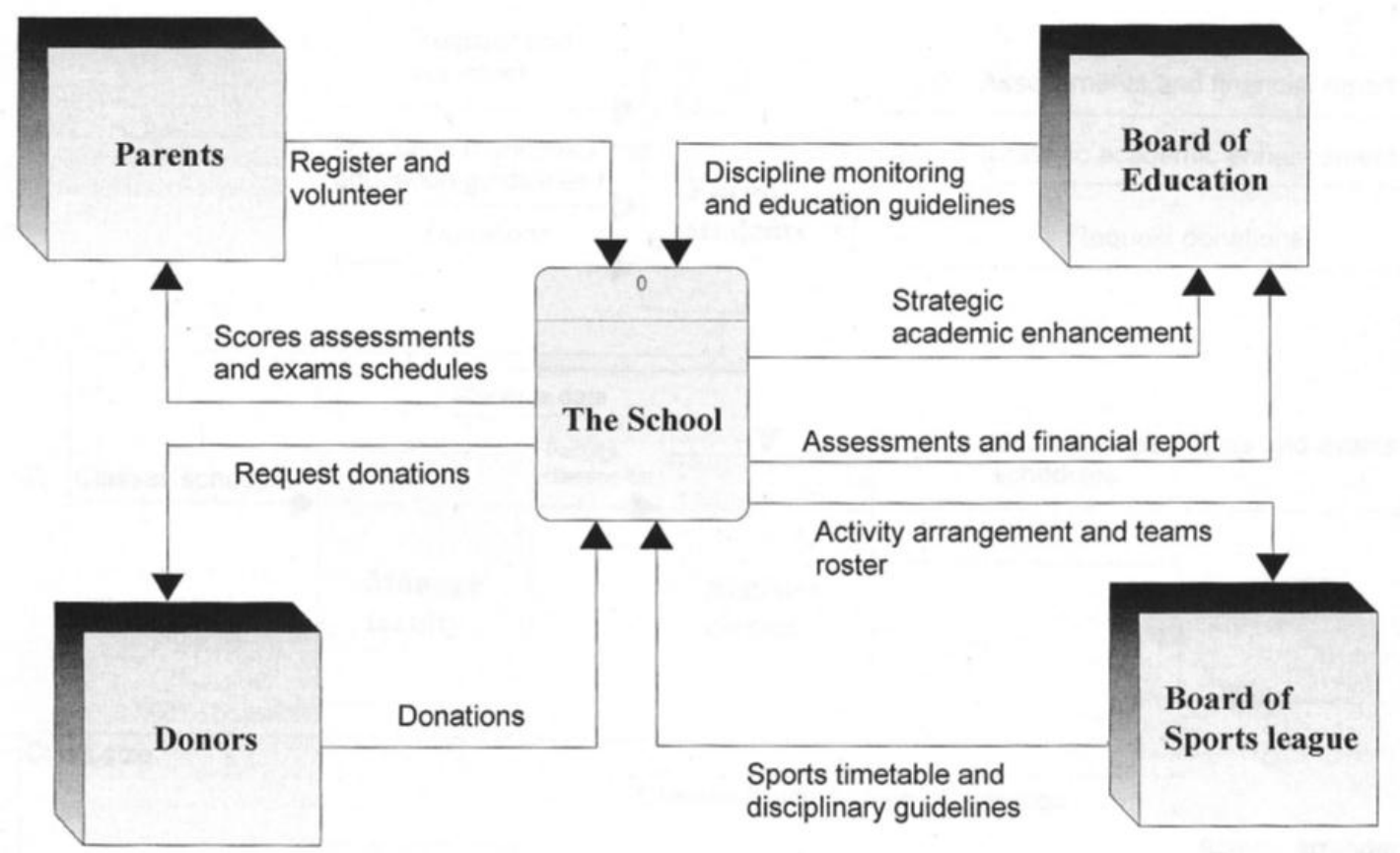

Figure 1. The school context DF diagram: Level 0 
The main external entities, rectangles, highlight the type of activity a school goes through to secure donations. The following four collated DFD diagrams illustrate the order of communicated information and data. These processes establish the school's strategic academic-criteria for its financial requirements. The donations are prerequisites to helping the advancement of strategic academic-developments.

Figure 2, the diagram houses all the relative high level processes. Enrollment, registration, managing faculty, and administering school services and activities are the major processes. The main subject of donation is based on the schools' academic needs, and is included within the enrollment process. The students' registration is intertwined with both academic standards and strategies and registering volunteers and donors. Schools justify the need for donations and financial contributions on the bases of the number of registered students, the academic standards and strategies, the school services and sports activities. The guidelines for such procedures and measures are encompassed in the enrollment process. Although many processes are diagrammed, only the parts dealing with donations will be diligently discussed, the rest will be alluded to as needed.

The need for academic enhancement is the core cause and trigger for petitioning all forms of donations and financial contributions. Methods to reach out donors are highlighted in the analysis phase of this paper. The process is structured to simplify handling of the database -routines' coding.

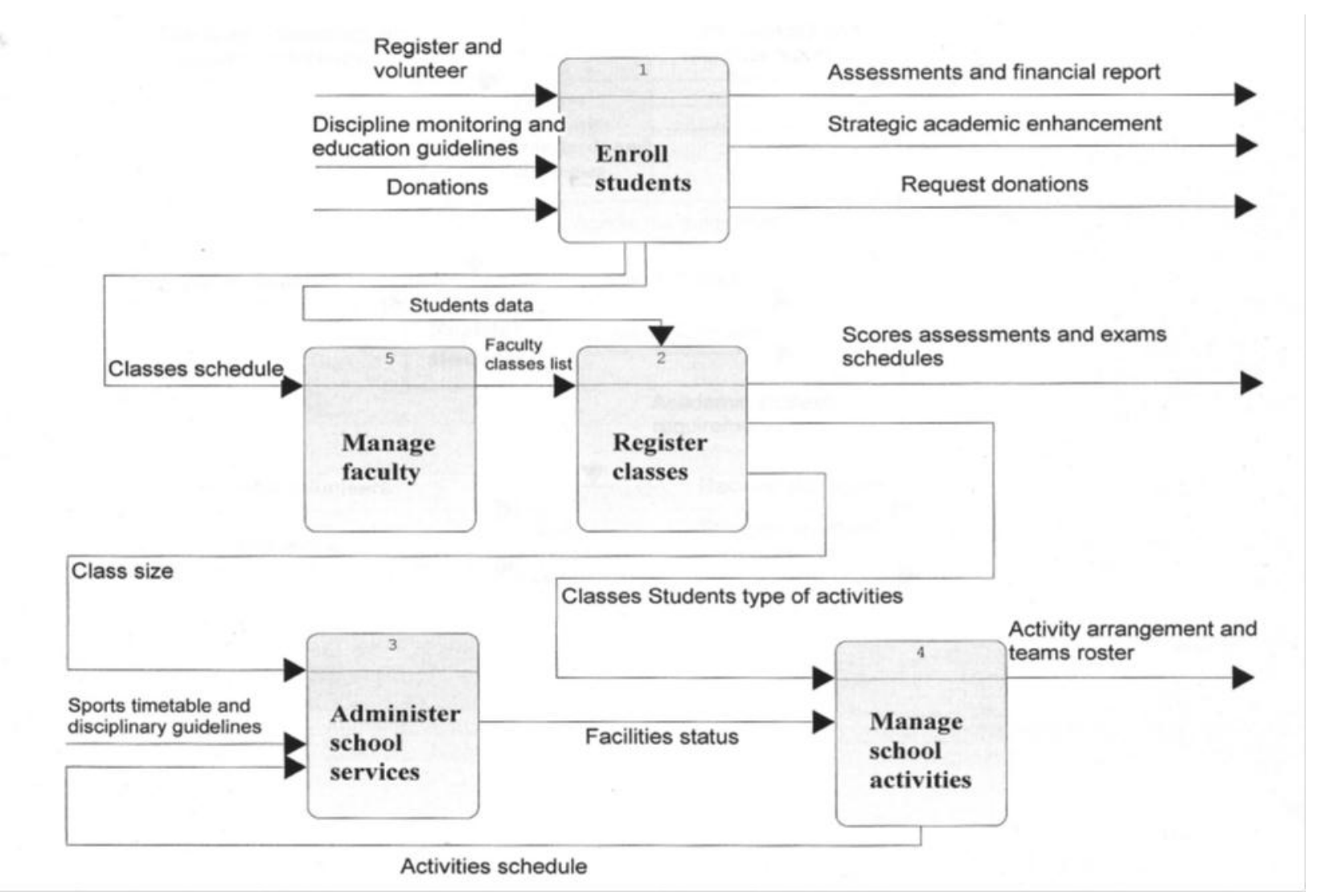

Figure 2. School system DF diagram: Level 1

Figure 4, details the second process in Figure 3, "accepting volunteers and donations". Registering the accepted volunteers and receiving donation from listed donors are processed. The academic enhancements and other related prerequisite services and activities determine the budget required. This budget defines and identifies the amount of financial contributions and material donations required by the school. Volunteers are advised on the school's academic standards and strategies and are well informed on the necessary services and activities in order to be able to demonstrate to donors the school's needs. 
The entire system in Figure 4 is dedicated to the relationship between the school and the volunteers. The information circulates between the related departments emphasizing the specifics of individual services and activities and cost details. This, in turn, provides donors with ample data on the contributions, how and where they are spent.

Donations are received within the process, "receive and process donations", where the selected registered volunteers are prepared for their related functions. The academic financing along with academic standards and regulations are delivered to a process where the cost and required expenditure are defined and refined in the process "determine cost of academic enhancement strategies", which produces the school's academic strategies.

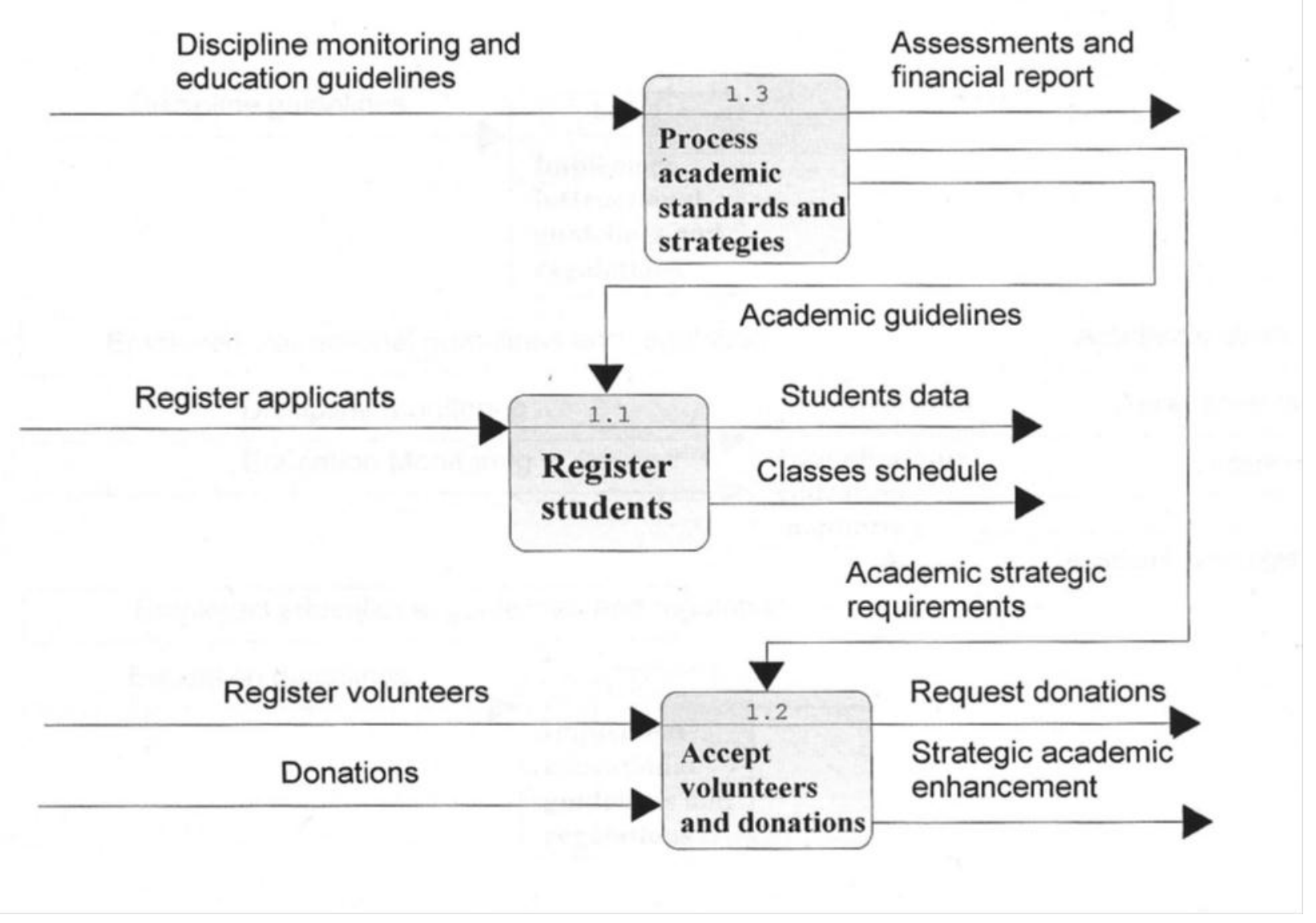

Figure 3. School enrollment system DF diagram: Level 2

The process "determine academic strategies" is fed data on the academic standards with a list of volunteers and services, and in turn feeds the process "determine cost of academic enhancement strategies" with data on academic strategies and regulations to determine the particulars of the academic strategic enhancements and detailed cost (Turban, Efraim; Aronson, Jaye E.; (1988), 81-83, 372-377). Services, in this case include all kinds of academic and sporting activities done by the separate departments of the school. The costs are based on individual hourly work payments and contracted functions, benefits or services requiring special skills. 


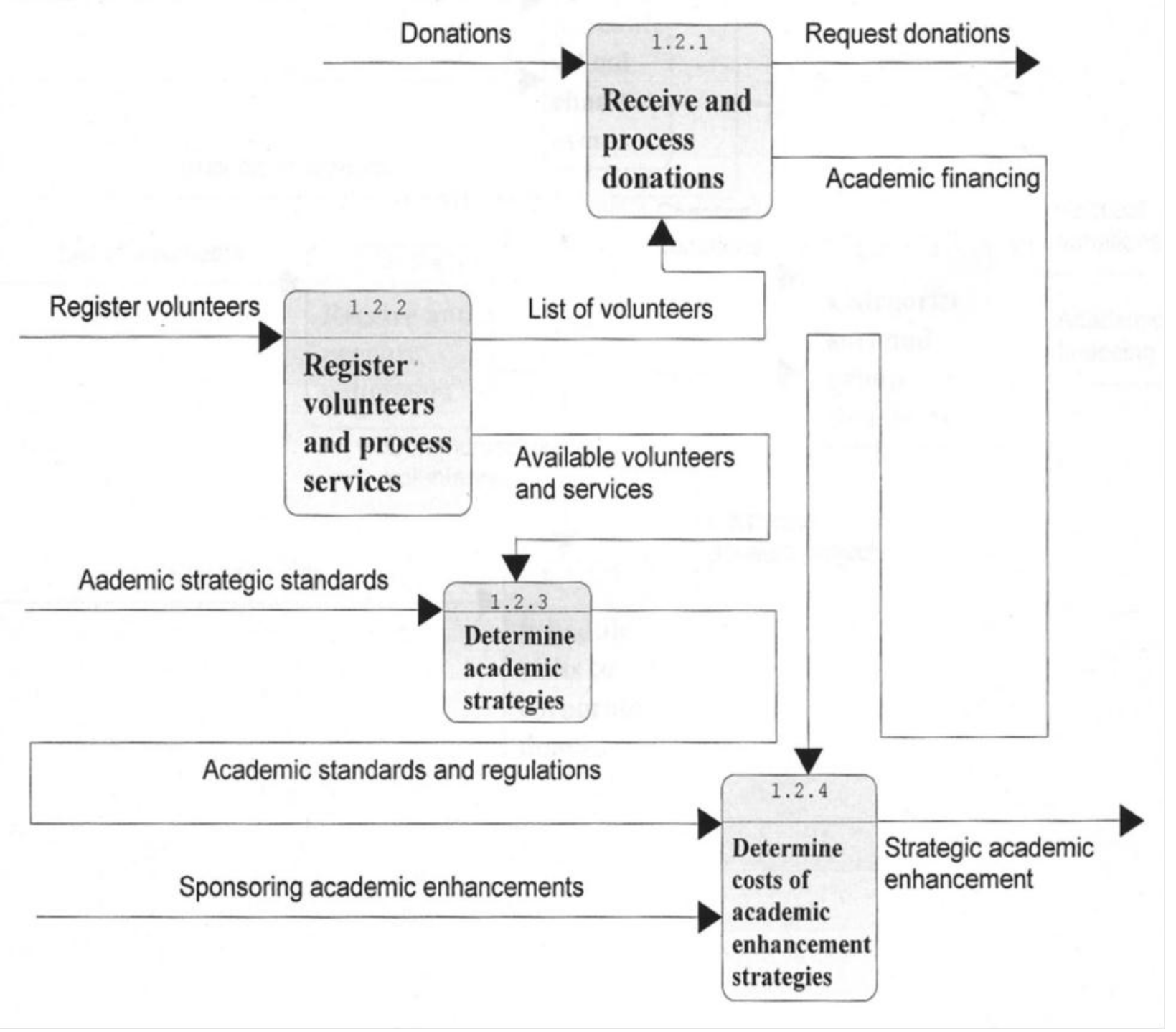

Figure 4. Accept volunteers and donations process: Level 3

Figure 5, details the process 1.2.1, "receive and process donations". This process describes the functions entailing the solicitation of all forms of donations and financial contributions by individuals, and corporations through individualized videolaudio demonstrations and or special charity events. The diagram encompasses four processes starting with receiving and preparing volunteers in the process. "Receive and prepare volunteers", followed by scheduling charity events in the process, "Schedule school charity events". This sets the stage for the process, "schedule visits to corporate donors"; in this process available wealthy individuals are also contacted and scheduled for private demonstrations on the school's needs. The final process deals with sorting and tabulating donation and financial contributions according to priority functions and school's academic strategies. 


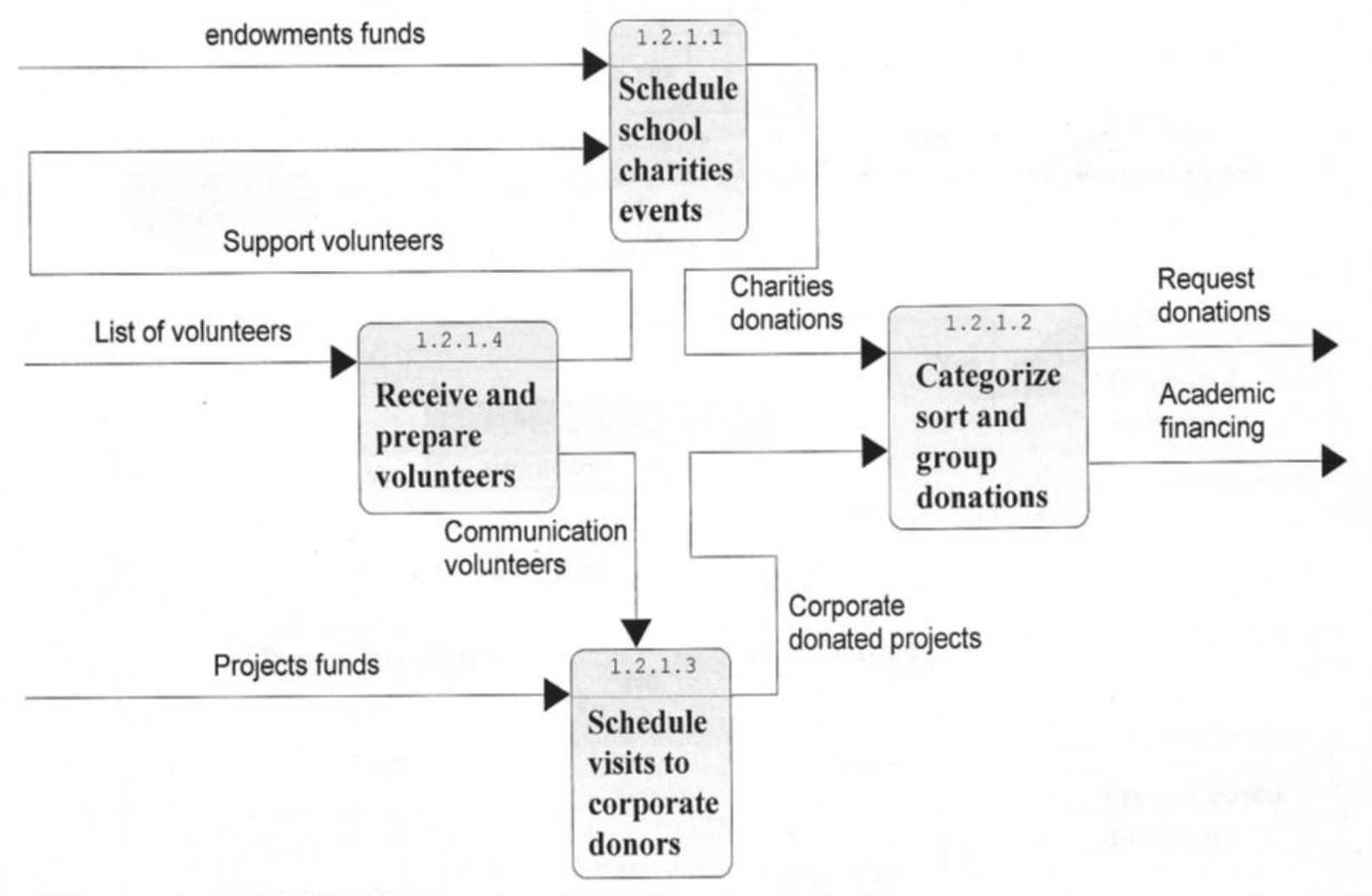

Figure 5. Receive and process donations process: Level 4

Following is a simplified version of the initial class code utilizing structures and constructs in which the three main structures of the system's proposed code are defined (Richard Smith, C++ standard; 11-19-2014):

class school_sys

$\{$ public:

struct students_data

\{ char st_name[20]; long st_ID; int st_age; char st_sex; float score;\};

struct volunteers_data

\{ char vol_name[20]; long vol_ID; int vol_age; char vol_sex; int don_size;\};

struct donors_data

\{ string donorname, address;

int donation;

students_data regData;// nested structure

volunteers_data donData;//nested structure

donors_data(string $d="$ ", string add=" ", int don=0)// the donors data constructor.

$\{$ donorname $=\mathrm{d}$;

address $=$ add;

donation $=\operatorname{don} ;\} ;\} ;\} ;$ 


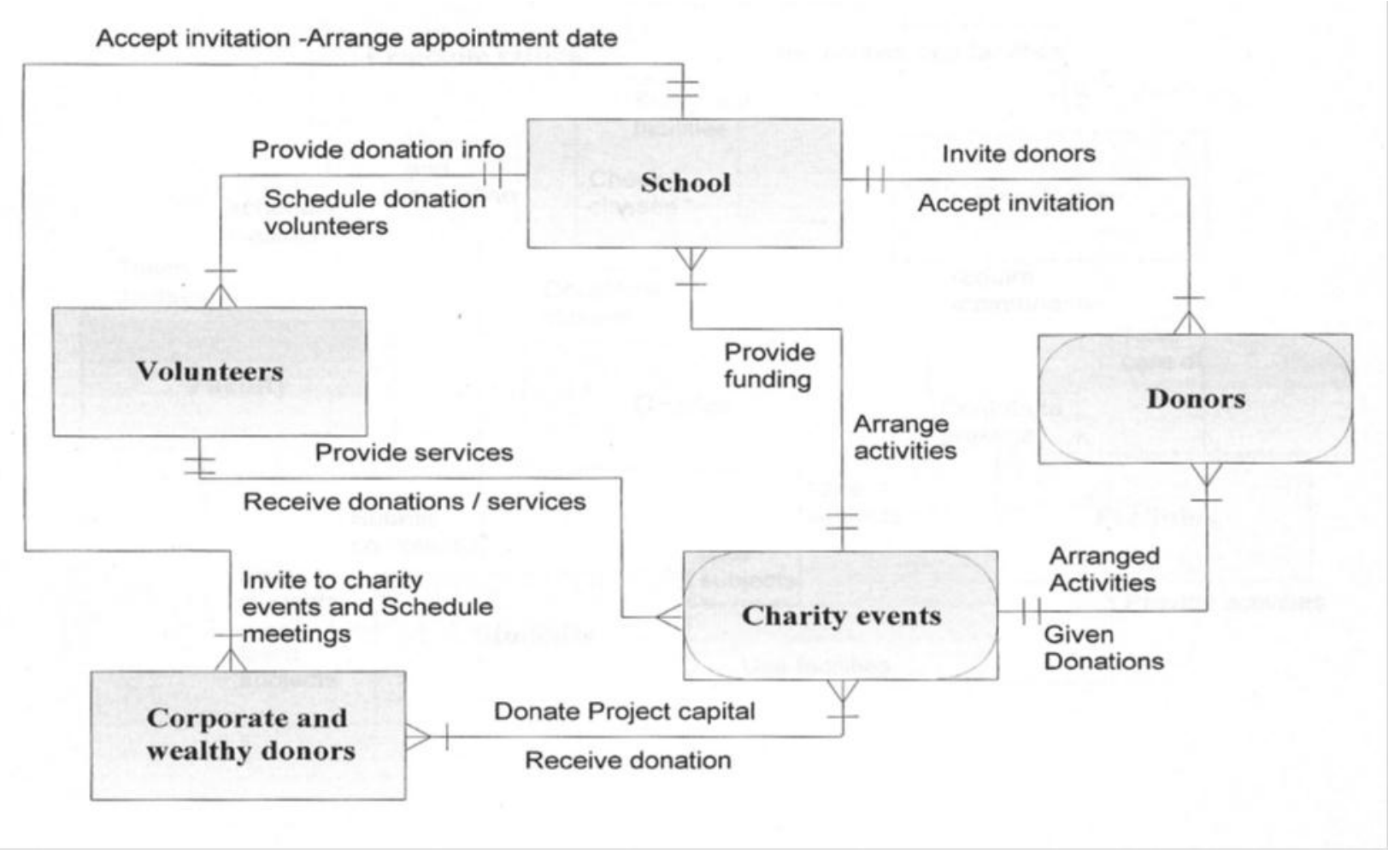

Figure 6. Donation decision process ERD

Figure 6, entails entity relationship diagram ERD for the donation's decision tree (Martin, James; McClure, Carma, 297-324). In this diagram the relationship between the main elements of the process are defined and integrated with emphasis on the data flows intrinsic to each entity. Following is a simplified code-example of the donors' identity and donations' amounts.

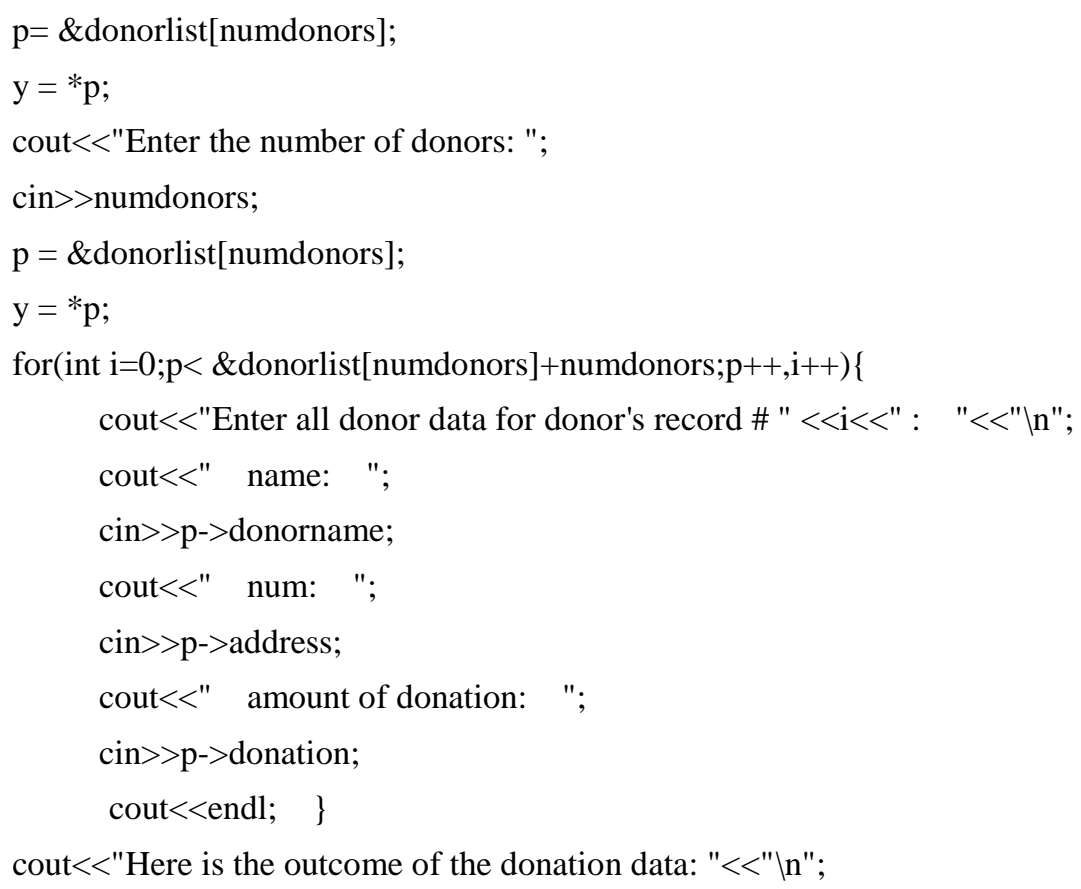




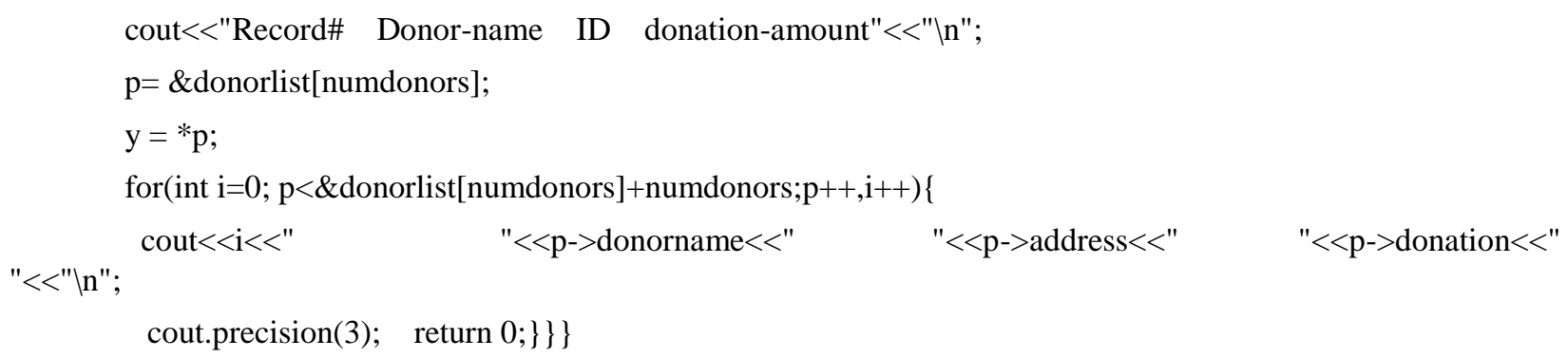

Another way for defining the process of introducing the main structures in order to simplify the coding of the software running the school database system is to separate the entities with separate structures and constructs. This may complicate the main function, however, improves performance and may reduce technical syntax and facilitate making modification. The following is another version of doing just that:

class school_sys

\{ public:

struct students_data

\{ string st_name; long st_ID; int st_age; string st_sex; float score;

students_data(string $\mathrm{sn}=$ " ", long $\mathrm{sID}=0$, int sage $=0$, string $\mathrm{sx}=$ " ", float $\mathrm{scr}=0.0$ )

$\{$ st_name $=\mathrm{sn}$;

st_ID = sID;

st_age $=$ sage;

st_sex $=\mathrm{sx}$;

score $=\mathrm{scr} ;\} ;\}$;

struct volunteers_data

\{ string vol_name; long vol_ID; int vol_age; string vol_sex; int don_size;

volunteers_data(string vn $="$ ", long vID $=0$, int vage $=0$, string vx $="$ ", int dize $=0$ )

$\{$ vol_name $=$ vn;

vol_ID = vID;

vol_age = vage;

vol_sex = vx;

don_size $=$ dize $;\} ;\}$;

struct donors_data

\{ string donorname, address;

int donation;

students_data regData;

volunteers_datadonData;

donors_data(string d=" ", string add=" ", int don=0)// the donors data constructor.

$\{$ donorname $=\mathrm{d}$;

address = add;

donation $=$ don; $\} ;\} ;\}$;

The above modified code makes adding to the functions and structures much easier than having to nest additional structures or entities within one of the applied structures, as done in the previous example, which limits the possibilities of adding entities or functions within any of the employed routines. The decision flow chart for the 
donation soliciting structure is displayed in Figure 7. It presents the logic implemented in prognosing the most appropriate technique to obtain the largest amount of financial contribution. It is explained in details in the following analysis of the proposed system.

The objective, here, is the method by which all related entities receive the considerations required to improve the quality of education and the educational environment. The analysis may seem tedious, however, conducive to a more inclusive social structure in which the benefits go beyond finance and are reaped by all associated parties.

The tables display the average amount of aggregate contributions over the past ten years, subject to the method used to solicit donations. The schools are allowed latitude for collecting donations utilizing a scheme of four options detailed as follows:

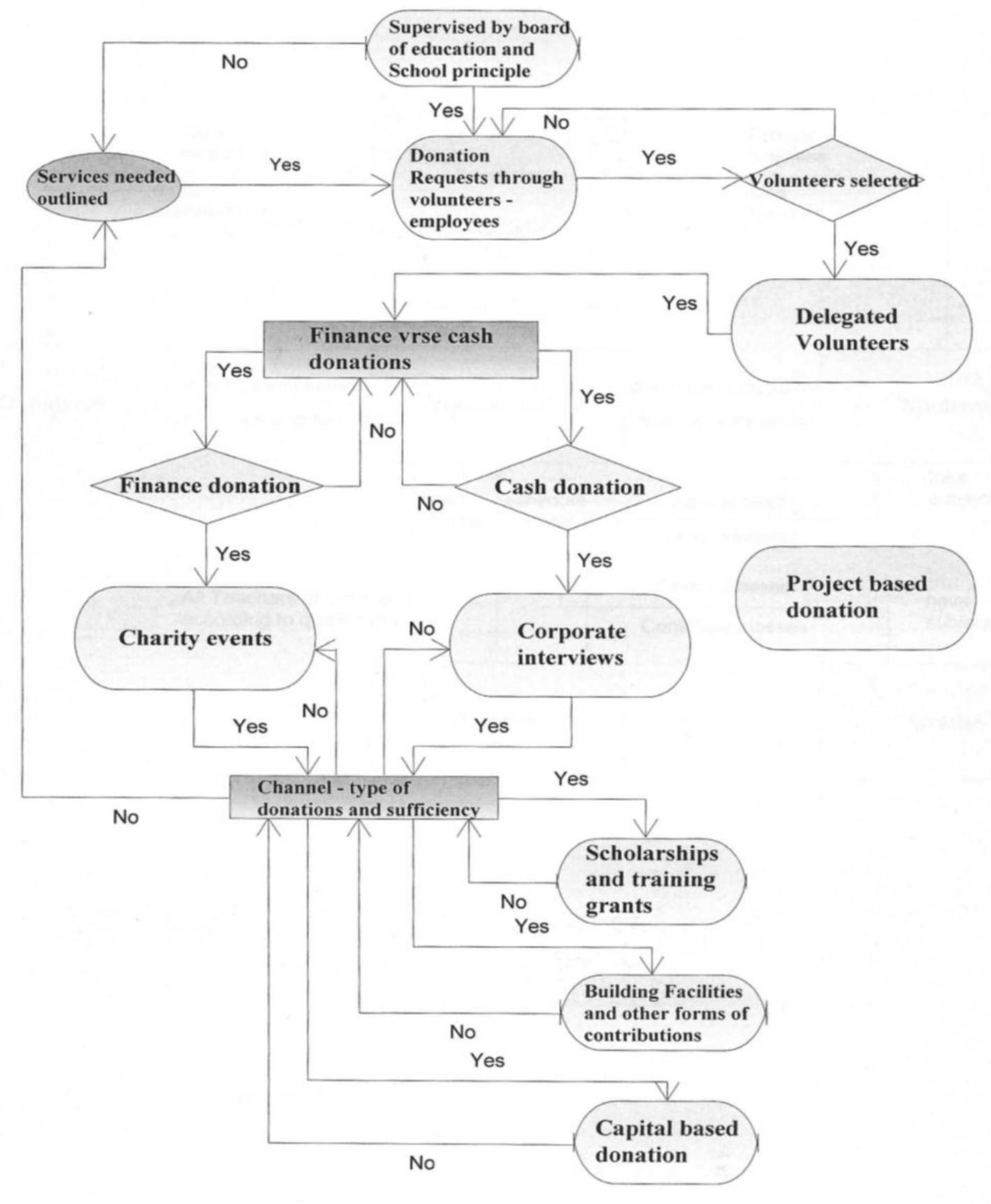

Figure 7. Donation soliciting activity diagram 


\section{Methodical Application}

Table 1. The donation arrangement system (Note 2)

Provisions and guidelines: There are 7 similar schools and colleges in this district. There are also $\sim 25$ large corporations and 40-50 very wealthy or well-off individuals. The population of the district is made up of $65 \%$ middle class, $15 \%$ upper middle class, $19.9 \%$ disadvantaged class. The rest are either very wealthy or just well-off. Each school is allowed one engagement for the selected number of corporations and or wealthy donors, and two charity events per academic year; one more charity event is allowed. There is an added provision that forces the schools to appropriate half of the proceeds of one of the charity events to the state's board of education. Corporate and or wealthy individuals participating in charity events are not selected for individualized demonstration engagements and vice versa.

The donors were divided into groups whose donations were subject to conditions according to their perspective on the schools performance qualitatively and quantitatively over the previous six years. Donors sought for video or audio demonstrations do not do charity events and vice versa. The following are Estimates of the change in donations over ten years.

a. The average total donation received per school of the 7 schools from private meetings/engagements with demonstrations to corporations and wealthy individuals over the last ten years have fluctuated between $\$ 1.5$ to $\$ 5$ million, subject to students' passing and success ratios over the previous 6 years. Condition: Perform $60 \%$ in at least one year during the last six years.

b. The average total donation received by any of the 7 schools from first annual charity events attended by middle and upper middle classes over the last ten years fluctuated between $\$ 0.4$ to $\$ 4.05$ million, subject to students' passing and success ratios over the previous 6 years.

c. The average total donation received by any of the 7 schools from the second annual charity event attended by middle and upper middle classes over the last ten years, fluctuated between $\$ 1.1$ to $\$ 4.3$ million, subject to students' passing and success ratios over the previous 6 years.

d. The average total donation received by any of the 7 schools from the all-in charity event attended by middle and upper middle classes; along with corporate and wealthy individuals over the last ten years, fluctuated between $\$ 0.9$ to $\$ 4.1$ million, subject to students' passing and Lowest Highest success ratios over the previous 6 years.

The following table is derived from Table 1. It provides the cumulative of each group of donation activities options. The objective is to group them is a way that does not contradict or conflict with the donation rules mentioned above.

Table 2. The annual donations activities proceeds' scheme. The following are the options extracted from the above donation events

\begin{tabular}{lllll}
\hline The total donation options & $\begin{array}{l}\text { Minimum }=\mathrm{m} \\
(\text { millions })\end{array}$ & $\begin{array}{l}\text { Maximum }=\mathrm{M} \\
(\text { millions })\end{array}$ & $\begin{array}{l}\text { Fluctuation value }(\mathrm{FV})=\mathrm{M}- \\
\mathrm{m}\end{array}$ \\
\hline 1. & Donation activities a, b and c & $\$ 3.0$ & $\$ 13.35$ & $\$ 10.35$ \\
\hline 2. & Donation activities a, b and d & $\$ 2.8$ & $\$ 13.15$ & $\$ 10.35$ \\
\hline 3. & Donation activities a, c and d & $\$ 3.5$ & $\$ 13.4$ & $\$ 9.9$ \\
\hline \multicolumn{2}{l}{ Total Donation Activity = TDA } & & \\
\hline
\end{tabular}

The following table utilizes both of the previous two tables. It provides the percentages of success in the schools used for this study. The average passing rate is the percentage of students with passing grades out of each of the schools picked for the study. The success rate is the percentage of students who graduated and continued to a successful higher education and secured employment afterwards. The product of the highest average passing rate and highest success rate provides us with the highest successful ratio. The product of the lowest passing average rate and the lowest success rate provides us with the lowest successful rate. 
Table 3. Approximate success rates of the examined school x, over previous six years

\begin{tabular}{|c|c|c|c|}
\hline \multicolumn{4}{|c|}{ Successful Ratio } \\
\hline \multirow{3}{*}{$\begin{array}{l}\text { Highest Average } \\
\text { Passing Rate } \\
\text { (HAPR) }\end{array}$} & Total highest Success Rate $($ THSR) $=$ Highest & Highest Successful & Lowest \\
\hline & $\begin{array}{l}\text { Success Rate + Lowest Success Rate }(\text { LSR })<= \\
100\end{array}$ & $\begin{array}{l}\text { Ration }(\text { HSFR })= \\
\text { HAPRxTHSR }\end{array}$ & $\begin{array}{l}\text { Successful Rate } \\
=\text { LAPR x LSR }\end{array}$ \\
\hline & $69 \%+25 \%=94 \%, \quad$ total $<100$ & $0.75 \% \times 94 \%=70.5 \%$ & $0.5 \times 25 \%=12.5$ \\
\hline $50 \%$ & THSR $=94 \%$ & 70.5 & 12.5 \\
\hline Average Passing Rate & Success Rate (SR) & \multicolumn{2}{|c|}{$\begin{array}{l}\text { Calculated successful Ratio }(\mathrm{CSFR})= \\
(\mathrm{APR} / 100) * \mathrm{SR}\end{array}$} \\
\hline Average passing rate $\mathrm{APR}=75 \%$ & Success rate $=35 \%$ & \multicolumn{2}{|l|}{$0.75 \times 35=26.25 \%$} \\
\hline Average passing rate $\mathrm{APR}=50 \%$ & Success rate $=35 \%$ & \multicolumn{2}{|l|}{$0.50 \times 35=17.5 \%$} \\
\hline Average passing rate $\mathrm{APR}=70 \%$ & Success rate $=25 \% \Rightarrow$ lowest success rate & \multicolumn{2}{|l|}{$0.70 \times 25=17.5 \%$} \\
\hline Average passing rate $\mathrm{APR}=75 \%$ & Success rate $=40 \%$ & \multicolumn{2}{|l|}{$0.75 \times 40=30 \%$} \\
\hline Average passing rate $\mathrm{APR}=50 \%$ & Success rate $=51 \%$ & \multicolumn{2}{|l|}{$0.50 \times 51=25.5 \%$} \\
\hline Average passing rate $\mathrm{APR}=73 \%$ & Success rate $=69 \% \Rightarrow$ highest success rate & \multicolumn{2}{|l|}{$0.73 \times 69=50.37 \%$} \\
\hline Average passing rate $=\mathrm{APR}$ & \multicolumn{3}{|c|}{ Highest successful ratio HSFR $=($ HAPR/100 $) \times$ THSR } \\
\hline \multicolumn{4}{|l|}{ Abbreviations: } \\
\hline Highest average passing rate $=$ HAPR & Total Highest Success rate $=$ THSR & \multirow{2}{*}{\multicolumn{2}{|c|}{ Lowest successful ratio $=$ LSFR }} \\
\hline \multicolumn{2}{|c|}{ Lowest average passing rate $=$ LAPR $\quad$ Lowest Success rate $=$ LSR } & & \\
\hline \multicolumn{4}{|l|}{ Definitions: } \\
\hline \multicolumn{4}{|c|}{ Average Passing Rate: Percentage of students receiving passing grades } \\
\hline \multicolumn{4}{|c|}{ Success Rate: Percentage of students who pass and go on to higher education and job security } \\
\hline \multicolumn{4}{|c|}{ Successful Ratio $(\mathrm{SFR})=(\mathrm{APR} / 100) \mathrm{X}$ SR and total highest successful ratio $(\mathrm{THSFR})=(\mathrm{HAPR} / 100) \mathrm{xTHSFR}$} \\
\hline \multicolumn{4}{|c|}{$\begin{array}{l}\text { Total Highest Success rate percentage }=\text { THSR: the highest combination of success rates percentages within the last } 6 \text { years not } \\
\text { exceeding } 100 .\end{array}$} \\
\hline
\end{tabular}


Table 4 is a derivative of the previous three tables. It provides us with all the possible percentages the three candidates can receive as the fair share of the donations' various components, grants, scholarships, projects and their equivalent in capital. Figure 8 clarifies the difficulties in understanding the details of this table.

Table 4. The activities proceeds calculated (Cooper, Robin; Kaplan, Robert S.; (1991);433-445)

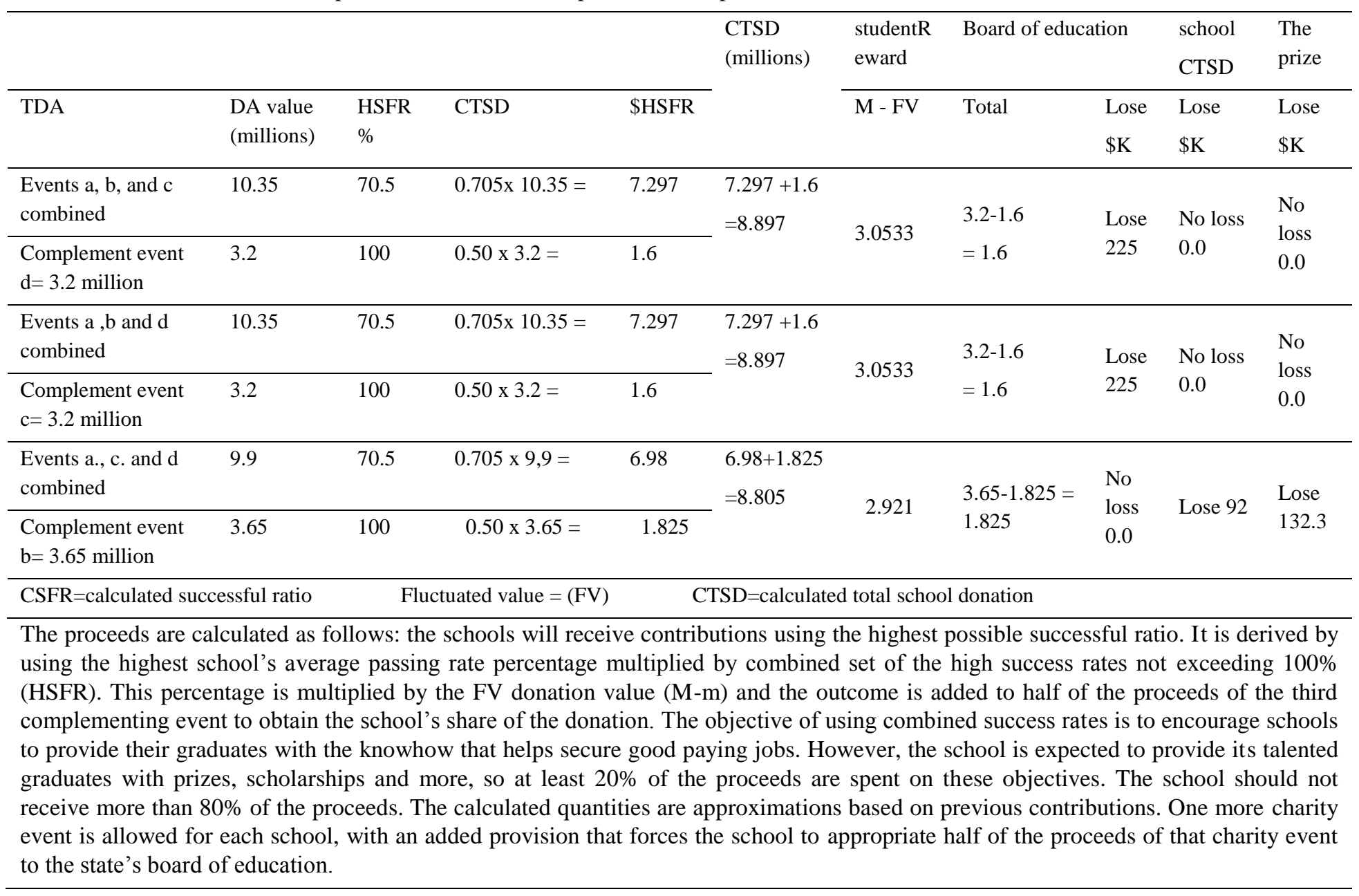

Table 1, provides the main details of the scheme and the structure of the contributions and their magnitude over the previous decade in the district's schools. Table 2, provides the accumulation of the donation sizes according to their activities and relative application. Table 3, provides the calculation of the donation percentages according to their success rates and successful ratios, as explained in the table. Table 4, provides us with the percentages of the donations according to the activities, and the recipients- entities, such as, in this case, schools, gifted students prizes, scholarships and the department of the board of education. The table is described more clearly in Figure 8.

\section{Results}

Table 4 and the schematic diagram in Figure 8, provide us with three options for distributing the contributions: the combination $(\mathrm{X} 1, \mathrm{X} 2)$ provide the school and students the highest possible ratio, and are accepted by the school and students; (Y1,Y2) provide school and students lowest ratio and are rejected by both; (Z1) provide the lowest ratio for the board of education and is rejected, but (Z2) provides the board of education the highest ratio and is accepted by the board. The purpose of acquiring donations is to help the schools provide better education, and provide students with incentive to endure and be competitive. The combination (X1 and X2) is best for both the school and the students, and the board of education will have to settle for the lowest proceeds. 


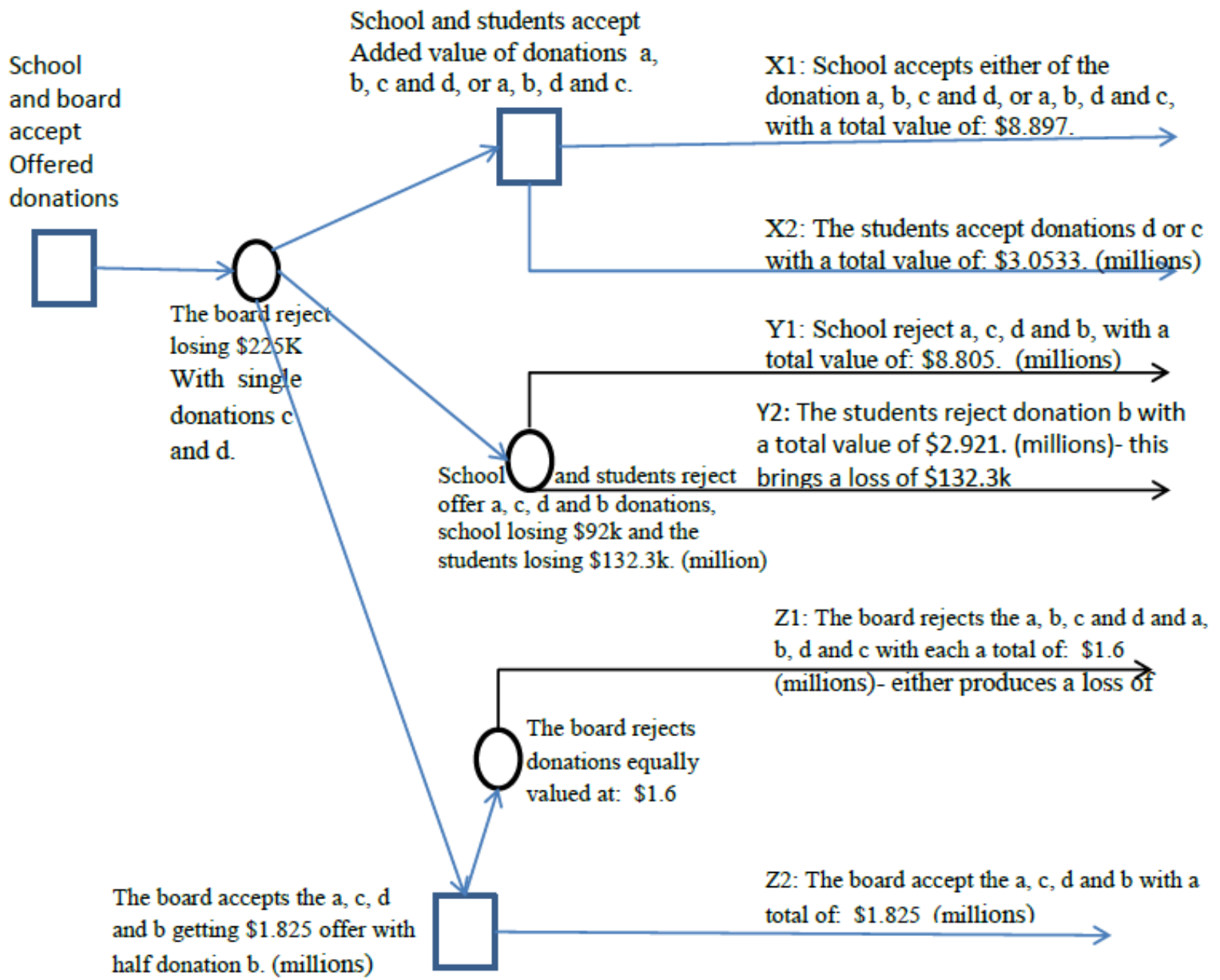

Figure 8. Donation decision tree scheme

\section{Conclusion}

Aside from the abundant possibilities for corrupt volunteers, corporate heads, school employees, to defraud the system, this scheme will undoubtedly provide the basis for sufficient contributions satisfying both the schools' system and the board of education. Documenting the activities and employing separate volunteers in each group representing the school for charity events, corporate heads meetings and wealthy individuals' presentations is necessary for protecting the integrity of the entire process. One of the advantages that can be a disadvantage of dealing with donations, donated educational trust funds and related functions is the lack of accountability to the IRS, and liability only to the individual's moral and ethical values. Schools' database systems' software should be required to include a few pages dedicated to donation solicitation and management. This will add to the academic educational value of the school and the board of education.

\section{References}

Clemen, Robert T. (1995). Making Hard Decisions: An Introduction to Decision Analysis (2 ${ }^{\text {nd }}$ ed.). Doxbury Press, Fuqua School of Business, Duke University.

Cooper, Robin, \& Kaplan, Robert S. (1991). The Design of Cost Management Systems: Text, Case, and Readings. Prentice Hall, Englewood Cliffs, NJ.

Eisner, Howard. (1997). Essentials of Project and Systems Engineering Management. John Wiley \& sons, Inc, New York. 
Martin, James, \& McClure, Carma. (1988). Structured Techniques: The Basis for Case. Printice Hall, Englewood Cliffs, New Jersey.

Ong, Paul, Jiménez, Silvia, Parent, Bill, \& Ong, Elena. (2014). The State of Donations: Individual Charitable Giving in Los Angelos. The 2014 State of the Nonprofit Sector in Los Anglos Report. Retrieved from www.civilsociety.ucla.edu

Richard Smith. Working Draft, Standard for Programming Language C++; Document Number: N4296, Date: 11-19-2014, Revises: N4140, Reply to: Richard Smith, Google Inc.

Turban, Efraim, \& Aronson, Jaye E. (1988). Decision Support Systems and Intelligent Systems. Printice Hall Upper Saddle River, New Jersey.

\section{Notes}

Note 1. https://www.cac-hc.org/get-involved/donate-2/ (this is an example of a system to solicit donations using many methods including the internet in Howard County (HC), in the state of Maryland, in the United States. This community council's members represent $\mathrm{HC}$ in soliciting donations for the county schools.)

Note 2. The plan is employed by the author in a book on Information and Engineering Management to be published in the future. It is also bits and bytes from plans employed separately in schools and colleges around the US. 